\title{
Electrocatalytic Reduction of Hydrogen Peroxide on Palladium-Gold Codeposits on Glassy Carbon: Applications to the Design of Interference-Free Glucose Biosensor
}

\author{
Elena Horozova, ${ }^{1}$ Totka Dodevska, ${ }^{2}$ Nina Dimcheva, ${ }^{1}$ and Ruska Mussarlieva ${ }^{1}$ \\ ${ }^{1}$ Department of Physical Chemistry, Plovdiv University, 24 Tsar Assen Street, 4000 Plovdiv, Bulgaria \\ ${ }^{2}$ Department of Inorganic and Physical Chemistry, University of Food Technology, 26 Maritsa Boulevard, 4002 Plovdiv, Bulgaria
}

Correspondence should be addressed to Nina Dimcheva, ninadd@uni-plovdiv.bg

Received 29 March 2011; Accepted 17 May 2011

Academic Editor: Newton Pimenta Neves Jr.

Copyright ( $) 2011$ Elena Horozova et al. This is an open access article distributed under the Creative Commons Attribution License, which permits unrestricted use, distribution, and reproduction in any medium, provided the original work is properly cited.

Following our previous studies on the catalytic activity electrochemically codeposited on graphite Pd-Pt electrocatalysts for hydrogen peroxide electroreduction, a series of glassy carbon electrodes were modified with $\mathrm{Pd}$ or $(\mathrm{Pd}+\mathrm{Au})$ deposits aiming at the development of even more efficient electrocatalysts for the same process. The resulting electrodes were found to be very effective at low applied potentials $(-100$ and $-50 \mathrm{mV}$ versus $\mathrm{Ag} / \mathrm{AgCl}, 1 \mathrm{M} \mathrm{KCl})$. The surface topography of the electrode modified with $\mathrm{Pd}+\mathrm{Au}$ mixed in proportions $90 \%: 10 \%$, exhibiting optimal combination of sensitivity and linear dynamic range towards hydrogen peroxide electrochemical reduction, was studied with SEM and AFM. The applicability of the same electrode as transducer in an amperometric biosensor for glucose assay was demonstrated. At an applied potential of $-50 \mathrm{mV}$, the following were determined: detection limit $(S / N=3)$ of $6 \times 10^{-6} \mathrm{M}$ glucose, electrode sensitivity of $0.15 \mu \mathrm{A} \mu \mathrm{M}^{-1}$, and strict linearity up to concentration of $3 \times 10^{-4} \mathrm{M}$.

\section{Introduction}

The ever-increasing interest towards electrochemical sensors has been driven by the numerous advantages they offer over the other analytical techniques, such as

(i) the simplicity of operating with electrical signals (current, potential, conductivity, or impedance);

(ii) compact and versatile instrumentation capable of supporting several different electrochemical techniques (steady state or dynamic) in a single device;

(iii) a possibility to finely tune the electrochemical detection and to customize it so that the tedious sample pretreatment stage could be avoided;

(iv) broad opportunities for miniaturization to afford portable devices, needing very small amounts of a sample (e.g., only several microlitres) to be analyzed;

(v) a possibility to perform an automated on-line monitoring, that is, a determination to be carried out directly in the system where the process/product of interest occurred.

Moreover, the selectivity of the analysis might be drastically improved through coupling sensor with a biological component for molecular recognition (enzymes, cells, or tissues), thus providing the opportunity to selectively determine the analyte in complex liquid matrices. These are the main prerequisites for their wide practical application in important spheres, such as medicine [1,2], food industry [3], and ecology [4].

A broad spectrum of oxidative enzymes (e.g., glucose oxidase, xanthine oxidase, etc.) is known to produce hydrogen peroxide as a by-product of the target reaction they catalyse in presence of molecular oxygen. Therefore, a large group of amperometric biosensors functions on the principle of measuring the current variation upon the addition of the enzyme substrate which is due to the electrochemical transformation (oxidation or reduction) of 
the generated $\mathrm{H}_{2} \mathrm{O}_{2}$. The biosensors based on registering the current from the electrochemical oxidation of the formed hydrogen peroxide suffer from poor selectivity, mostly due to the high operational potentials, at which the compounds normally attending biological liquids (organic acids, neurotransmitters, and drugs) are co-oxidised, thus leading to overestimated analyte levels. Alternatively, reducing electrochemically $\mathrm{H}_{2} \mathrm{O}_{2}$ at low working potentials (usually around $0 \mathrm{~V}$ versus $\mathrm{Ag} / \mathrm{AgCl}$ ) [5], where interfering substances are electrochemically inert, allows for a much more selective assay of the analyte. In respect to studies on the surface modified with micro- and nanostructures carbonaceous electrodes as efficient electrocatalysts of hydrogen peroxide, both oxidation and reduction [6-13] are currently on high demand.

Various types of carbonaceous materials have been investigated most often as modified electrodes for determining $\mathrm{H}_{2} \mathrm{O}_{2}$ : graphite [6, 14], glassy carbon $[7,8,10,15-19]$, carbon-paste electrodes $[20,21]$, carbon nanotubes [2224], and so forth. With these electrodes, the selectivity of the electrochemical response to hydrogen peroxide is improved by using different catalytically active modification components: transition metals and their oxides [15, 21], platinum metals, dispersed on their own or mixed with other platinum metals $[7,25]$, and with nanostructured composite films $[8,26]$. Studies aimed at the electroanalytical detection of $\mathrm{H}_{2} \mathrm{O}_{2}$ with micro- and nanostructured carbon films containing metal particles $(2-5 \mathrm{~nm})$, such as $\mathrm{Pt}, \mathrm{Ni}, \mathrm{Cu}$, and $\operatorname{Ir}[26]$, have become common in recent years.

In electrochemical sensor technologies, special attention is paid to carbon nanotubes (CNTs) as a promising electrode material. CNTs have demonstrated to possess a unique combination of excellent structural, mechanical, and electrochemical characteristics [22]. CNT-based electrodes, promoted with metal nanoparticles, are distinguished with their high catalytic activity and have been successfully used for detecting $\mathrm{H}_{2} \mathrm{O}_{2}[23,24]$. The modification was performed through the adsorption of nanoparticles from colloidal solutions or through electrodeposition from a solution of the salt of the respective metal. The second approach is often preferred due to the possibility of strict and accurate control allowing for the high reproducibility of the modification procedure. Contemporary studies proved the electrodeposition as an attractive and cheap method for building-up nanosized metal structures, which does not require expensive equipment $[27,28]$. By varying the conditions of modification (applied potential, composition of the electrolyte, deposition time, nature of the carrier, etc.), micro- and nanostructured composite metal deposits with high electrocatalytic activity can be obtained.

Our research has shown that highly porous graphite materials, modified through potentiostatic deposition of $\mathrm{Pt}, \mathrm{Pd}$, and mixtures of $(\mathrm{Pd}+\mathrm{Pt})$ and $(\mathrm{Pd}+\mathrm{Au})$ in varied proportions, prove to be effective electrocatalysts for the reduction of hydrogen peroxide at low working potentials [9, 10]. In addition, modified graphites were characterised with a simple modification protocol, high operational stability over a wide $\mathrm{pH}$-range, and high operational stability with retaining catalytic activity for over 1 year that motivated us to use them as electrochemical transducers in the design of amperometric biosensors based on the electroreduction of hydrogen peroxide. This study continues our research in the above-mentioned direction, with glassy carbon being the solid support to be modified with microquantities of pure $\mathrm{Pd}$ and a mixture $(\mathrm{Pd}+\mathrm{Au})$ deposited electrochemically on it. The choice of the carbon material, glassy carbon, is motivated by its high mechanical and chemical stability in aggressive media, and above all by its fullerene-related structure [29], that is, properties that distinguish it from graphite. In addition, substituting one of the components of the catalytically active phase, Pt with gold would potentially affect the catalytic activity towards the target reaction $\left(\mathrm{H}_{2} \mathrm{O}_{2}\right.$ electroreduction), and the new data would provide us with a better understanding of the factors affecting the catalytic process as a whole. Based on the above, the present study deals with the development of an efficient and selective electrocatalyst for the reduction of $\mathrm{H}_{2} \mathrm{O}_{2}$ through modification of glassy carbon with microdeposits of $\mathrm{Pd}$ and a mixture of $(\mathrm{Pd}+\mathrm{Au})$. Their applicability as transducers in amperometric biosensors, based on hydrogen peroxide producing oxidoreductases, is also demonstrated.

\section{Experimental}

2.1. Materials. Glucose oxidase (GOx) (E.C. 1.1.3.4) from Aspergillus niger (Fluka Biochemica), with homogeneous activity of $198 \mathrm{U} \mathrm{mg}^{-1}$ (1 U corresponds to the amount of the enzyme which oxidizes $1 \mu \mathrm{moL}$ glucose per min at $\mathrm{pH} 7.0$ and $25^{\circ} \mathrm{C}$ ); D-glucose monohydrate (Valerus, Sofia, Bulgaria). Hydrogen peroxide and chemicals used for preparing buffer solutions, $\mathrm{Na}_{2} \mathrm{HPO}_{4} \times 12 \mathrm{H}_{2} \mathrm{O}$, citric acid, $\mathrm{KOH}$, and $\mathrm{H}_{3} \mathrm{PO}_{4}$, were purchased from Fluka. All solutions were prepared with double-distilled water. The $\beta$-D-glucose solution $\left(5 \times 10^{-3} \mathrm{M}\right.$ in phosphate-citrate buffer, $\left.\mathrm{pH} 7.0\right)$ was allowed to mutarotate for $24 \mathrm{~h}$ before use.

2.2. Preparation of the Electrodes. Glassy carbon (GC) lamellae with a geometric surface $S_{\text {geom }}=1.35 \mathrm{~cm}^{2}$ were used. The catalytically active components were deposited in potentiostatic regime $\left(E_{\text {deposit }}=+0.05 \mathrm{~V}\right.$ versus reversible hydrogen electrode) via a brief electrolysis $\left(t_{\text {deposit }}=10 \mathrm{~s}\right)$ from the following electrolytes: $2 \%$ solution of $\mathrm{PdCl}_{2}$ in $0.1 \mathrm{M} \mathrm{HCl}$, alone or mixed with $2 \%$ solution of $\mathrm{HAuCl}_{4}$ in $0.1 \mathrm{M} \mathrm{HCl}$ in the following volume to volume ratios: $90 \%: 10 \%, 70 \%: 30 \%$, or $50 \%: 50 \%$. The respective molar proportions of $\mathrm{Pd}$ to $\mathrm{Au}$ in the electrodeposition baths have been determined to be $17: 1 ; 9: 2 ; 2: 1$. The surface coverage was estimated to be $c a .18 \mu \mathrm{g} \mathrm{cm}^{-2}$. The prepared electrodes were allowed to age for 3-5 weeks until the stabilization of the surface occurs. By the end of ageing period, the chronoamperometric data showed a decrease of the active electrode surface with $15 \%$.

The electrodes will be further denoted in the text as electrodes types A, B, C, and D as follows:

(i) glassy carbon modified with individual Pd (electrode type A); 
(ii) glassy carbon modified with $\mathrm{Pd}+\mathrm{Au}$ mixed in a ratio of $90 \%: 10 \%(w / w$, electrode type B);

(iii) glassy carbon modified with $\mathrm{Pd}+\mathrm{Au}$ mixed in a ratio of $70 \%: 30 \%(w / w$, electrode type $C)$;

(iv) glassy carbon modified with $\mathrm{Pd}+\mathrm{Au}$ mixed in a ratio of 50\%:50\% (w/w, electrode type D).

2.3. Apparatus and Measurements. All electrochemical measurements were performed in a three-electrode cell with separated compartments (working volume $10-15 \mathrm{~mL}$ ). An $\mathrm{Ag} / \mathrm{AgCl}, 1 \mathrm{M} \mathrm{KCl}$ electrode was used as a reference electrode, and platinum wire as a counter electrode. The electrochemical setup also involved a bipotentiostat, type BiPAD (TACUSSEL, Villeurbanne, France); a generator, type EG-20 (Elpan, Lubawa, Poland); a digital voltmeter, type 1AB105 (ZPU, Pravets, Bulgaria). The solutions were softly bubbled with argon during the measurements, in order to decrease the background current, but not to completely deaerate the solutions. For the experiments with the enzyme electrodes, the access of oxygen to the electrolyte was assured by keeping the cell open. The operational characteristics of the series-modified electrodes were examined by the polarization curves' method in potentiostatic regime (phosphate-citrate buffer, $\mathrm{pH}$ 7.0). For maintaining constant temperature a thermostat UH (VEB MLW Prüfgeräte-Werk, Medingen, Germany) was used. The $\mathrm{pH}$ of the buffer solutions was adjusted with a pH-meter OP-208 (Radelkis, Budapest, Hungary).

\section{Results and Discussion}

3.1. Electrocatalytic Reduction of Hydrogen Peroxide. The steady-state polarization curves on glassy carbon electrodes, modified with deposits of Pd only (type A electrode) and with the mixtures of $(\mathrm{Pd}+\mathrm{Au})$ (types $\mathrm{B}, \mathrm{C}$, and $\mathrm{D}$ electrodes) in presence of hydrogen peroxide recorded over the potential range from -250 to $+250 \mathrm{mV}$ (versus $\mathrm{Ag} / \mathrm{AgCl}$ ) at $25^{\circ} \mathrm{C}$, are shown in Figure 1.

Cathode currents in presence of $\mathrm{H}_{2} \mathrm{O}_{2}$ resulting from its electrochemical reduction were observed over the studied range of potentials for all four modified glassy carbon electrodes. In the case of a pure glassy carbon electrode and glassy carbon modified with deposits of Au only, no such currents were noted (not shown). Regions of almost limiting current values (plateau) around and below $0 \mathrm{~V}$ are observable on the polarization curves for electrodes of types A, B, C, and $\mathrm{D}$, which indicates that each of the modified electrodes might be potentially useful in the electroanalytical assay of hydrogen peroxide. The plateau region was found to be dependent on the nature of the catalytically active modifier (deposits of Pd only, or of palladium-gold mixtures in varied proportions). Limiting current values over the potential range from -100 to $+50 \mathrm{mV}$ characterise two of the glassy carbon electrodes: the one modified with Pd only (type A, closed circles) and the type B electrode (open squares). Just as wide is the plateau for the type $\mathrm{C}$ electrode (open triangles), though in the potential region from -50 to $+100 \mathrm{mV}$. The type D electrode plateau (asterix), spanning the range

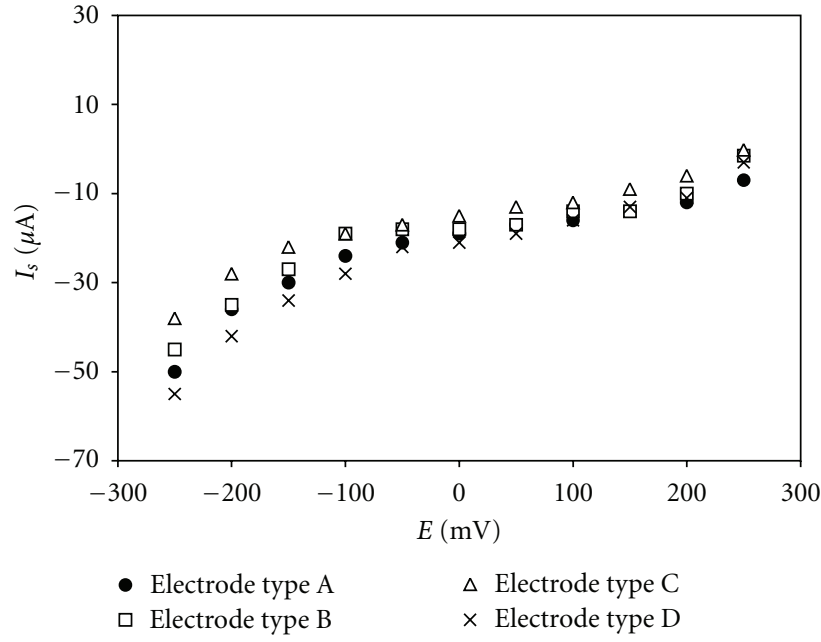

FIGURE 1: Steady-state current as a function of the applied potential at modified glassy carbon electrodes in $0.1 \mathrm{M} \mathrm{H}_{2} \mathrm{O}_{2}$ present; phosphate-citrate buffer, $\mathrm{pH}$ 7.0; reference electrode $\mathrm{Ag} / \mathrm{AgCl}(1 \mathrm{M} \mathrm{KCl})$; temperature $25^{\circ} \mathrm{C}$.

from -50 to $+50 \mathrm{mV}$, is the narrowest. Figure 1 shows that besides the width of the plateau, the activity of the glassy carbon electrodes in hydrogen peroxide electroreduction also depends on the composition of the catalytically active phase. The activity of the electrodes estimated as the values of the electrode response towards hydrogen peroxide in the plateau region decreases in the order

$$
\text { type } \mathrm{D} \sim \text { type } \mathrm{B}>\text { type } \mathrm{A}>\text { type } \mathrm{C} \text {. }
$$

With all types of glassy carbon, the dependence of the electrode signal (cathode current) on the $\mathrm{H} 2 \mathrm{O} 2$ concentration at three potentials from the plateau region -0 , -50 , and $-100 \mathrm{mV}$ (versus $\mathrm{Ag} / \mathrm{AgCl}$ ) was studied in a phosphate-citrate buffer, $\mathrm{pH}$ 7.0, at room temperature. The electrode response was found to increase linearly with the substrate concentration at the three chosen potentials, with sensitivities $(\mathrm{dI} / \mathrm{dC}$, determined from the linear part of calibration graphs, $n=3$ ) depending on both the applied potential and the type of the modifying catalytically active component (Figure 2).

For modified glassy carbon of types B, C, and D, the sensitivity increases as the working potential shifts to the negative direction. As a general rule, the electrode sensitivity at potentials -50 and $-100 \mathrm{mV}$ was found to be between 1.2 and twice as high as the sensitivity registered at $0 \mathrm{~V}$ (Table 1 ). For glassy carbon modified with Pd only (type A), there were no differences observed in the values of the electrode signal over the same potential range. The linear dynamic range of the electrode signal (in $\mu \mathrm{M}$ ) also differs for all electrodes as dependent on the applied potential and on the type of the modifying component For the type A electrode; however, the linearity of the signal, as well as the sensitivity, increases as the potential shifts negatively. For the other three electrodes-of types $\mathrm{B}, \mathrm{C}$, and $\mathrm{D}$, there is no correlation between the linearity of the response and the shifts of the potential in the cathode direction. There is no dependence 


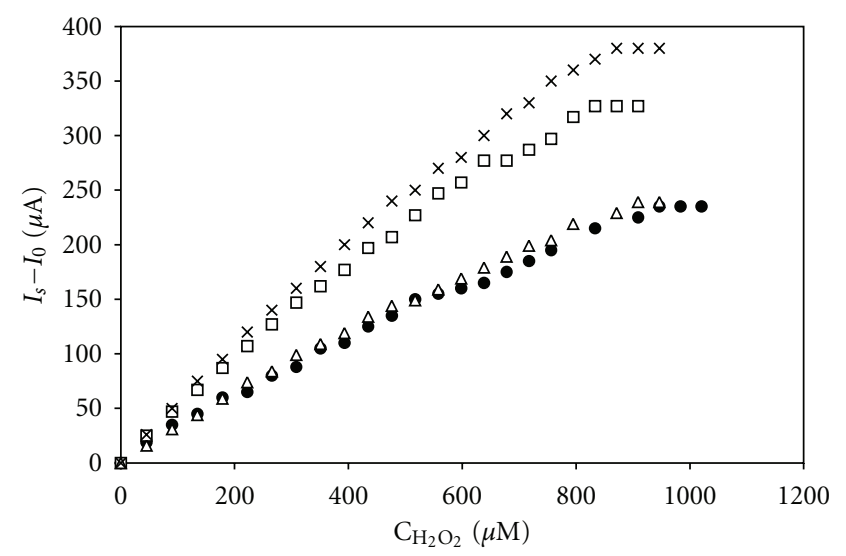

- Electrode type A $\Delta$ Electrode type C

$\checkmark$ Electrode type B $\times$ Electrode type D

FIgURE 2: Background subtracted steady-state response of the electrode type B (Pd to Au in atomic ratio $90 \%: 10 \%$ on glassy carbon) as a function of hydrogen peroxide concentration at an applied potential of $-100 \mathrm{mV}(\mathrm{Ag} / \mathrm{AgCl}, 1 \mathrm{M} \mathrm{KCl})$; phosphate-citrate buffer, $\mathrm{pH} 7.0$; temperature $25^{\circ} \mathrm{C}$.

between the linearity of the signal and the percentage of $\mathrm{Pd}$ and $\mathrm{Au}$ in the microdeposits of the modifying mixture, either.

The dependencies of current on $\mathrm{H}_{2} \mathrm{O}_{2}$ concentration over the chosen potential region $(0,-50$ and $-100 \mathrm{mV})$ were examined under strictly isothermal conditions at ambient temperatures of 25 and $35^{\circ} \mathrm{C}$ (chosen in view of the anticipated application of the examined electrodes as biosensor transducers). Experimental data show that this 10degree increase of the temperature affects in a very different way the rate of peroxide electroreduction on the modified GCs (current). While for the first two types of glassy carbon (A- and B-type electrodes), lower currents and hence poorer electrode sensitivities were observed at the higher temperature, for the C- and D-type GC with increasing temperature, higher currents and electrode sensitivities were noticed. These experimental results suggest that in the studied process hydrogen peroxide is consumed simultaneously by two alternative reaction pathways, namely, (i) heterogeneouscatalytic decomposition and (ii) electrocatalytic reduction. Most probably, with the first two types of electrode materials (A- and B-type GC), the purely heterogeneous-catalytic decomposition of hydrogen peroxide successfully competes with the electroreduction reaction, thus lowering the effective concentration of peroxide. This might be due to the availability of numerous different catalytically active sites formed on the surface of the A- and B-type of modified glassy carbon. With the second two electrode materials ( $\mathrm{C}$ - and D-type), however, there is no such a strong impact of the heterogeneous catalytic pathway on the overall process, and therefore the effect of temperature on the rate of the $\mathrm{H}_{2} \mathrm{O}_{2}$ electroreduction can be quantified by calculating the effective activation energy according to the equation

$$
\ln \frac{I_{T_{2}}}{I_{T_{1}}}=\frac{E_{a}}{R}\left(\frac{1}{T_{1}}-\frac{1}{T_{2}}\right) .
$$

The activation energy of the electrochemical reduction of hydrogen peroxide on the $\mathrm{C}$ type GC was found to be virtually the same over the studied range of potentials: $E_{a}=$ $31.6 \pm 1.9 \mathrm{~kJ} \mathrm{moL}^{-1}$. Similarly, the activation energy of $\mathrm{H}_{2} \mathrm{O}_{2}$ electroreduction on the $\mathrm{D}$ type electrode has been found to be independent of the working potential over the chosen potential region; however, the temperature effect on the reaction rate was much lesser, and the activation energy was calculated to be $11.2 \pm 1.9 \mathrm{~kJ} \mathrm{moL}^{-1}$. The low effective activation energy values as well as their independence of the working potential suggest that the electrocatalytic process in both cases is limited by diffusion.

From the basic operational characteristics of glassy carbon electrodes (Table 1), it is evident that the glassy carbon electrodes with the highest sensitivity $(\mathrm{dI} / \mathrm{dC})$ are the ones of types B and D at working potentials of -50 and $-100 \mathrm{mV}$. At a potential of $-50 \mathrm{mV}$, the type B electrode is characterized by a longer linear dynamic range of the calibration graph (up to $980 \mu \mathrm{M}$ ) as compared to the type D electrode (up to $760 \mu \mathrm{M}$ ).

The surface topography of electrode type B was studied by means of scanning electron microscopy (SEM) and atomic force microscopy (AFM). SEM photograph (Figure 3(a)) shows that the catalytically active phase (atomic ratio of $\mathrm{Pd}$ to $\mathrm{Au} 90 \%: 10 \%$ ) is deposited on the glassy carbon support in the form of well-defined oval formations with a size of 100 to $500 \mathrm{~nm}$, while the AFM image (Figure 3(b)) gives a much detailed information about the substructure of the deposits; they consist of fine grains with nearly spherical shape and approximate diameter of 10-20 $\mathrm{nm}$.

Ensuring a high selectivity of the analysis is a factor of key importance when designing amperometric biosensors. In this connection, the response of the type B electrode was studied in the presence of electrochemically active substances, which usually attend biological fluids. At potentials of -50 and $-100 \mathrm{mV}$, no electrode response was registered in the presence of uric acid, ascorbic acid, glutathione, and paracetamol, in concentrations of up to $700 \mu \mathrm{M}$, which largely exceed the possible physiological levels. In addition, for the type B electrode, the lowest background currents at potentials of -50 and $-100 \mathrm{mV}$ were registered as well. The discussed advantages of the modified glassy carbon electrode of type B were the main prerequisites in choosing it as a transducer in designing an amperometric glucose biosensor.

3.2. Glucose Oxidase Enzyme Electrode. The high activity and selectivity, the sufficiently long dynamic range of the response, the low background currents, and the great number of catalytically active centres of glassy carbon modified with microquantities of ( $\mathrm{Pd}$ to $\mathrm{Au} \mathrm{90 \% :10 \% )} \mathrm{were} \mathrm{the} \mathrm{main}$ prerequisites for its use as a basic biosensor transducer. On it, by immobilizing GOx in accordance with a previously reported procedure [10], a new glucose oxidase enzyme electrode was developed. The possibility to determine quantitatively glucose at potentials of -100 and $-50 \mathrm{mV}$ in a phosphate-citrate buffer $\mathrm{pH} 7.0$, at temperatures of $25^{\circ} \mathrm{C}$ and $35^{\circ} \mathrm{C}$ (Table 2 ), was examined.

The presented data shows that a rise of the temperature with $5^{\circ} \mathrm{C}$ results in an increased current response which is 


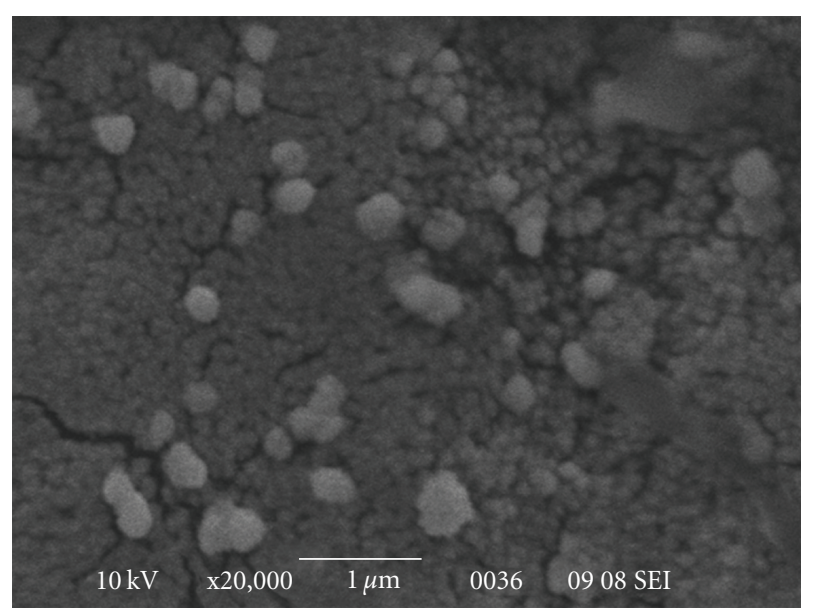

(a)

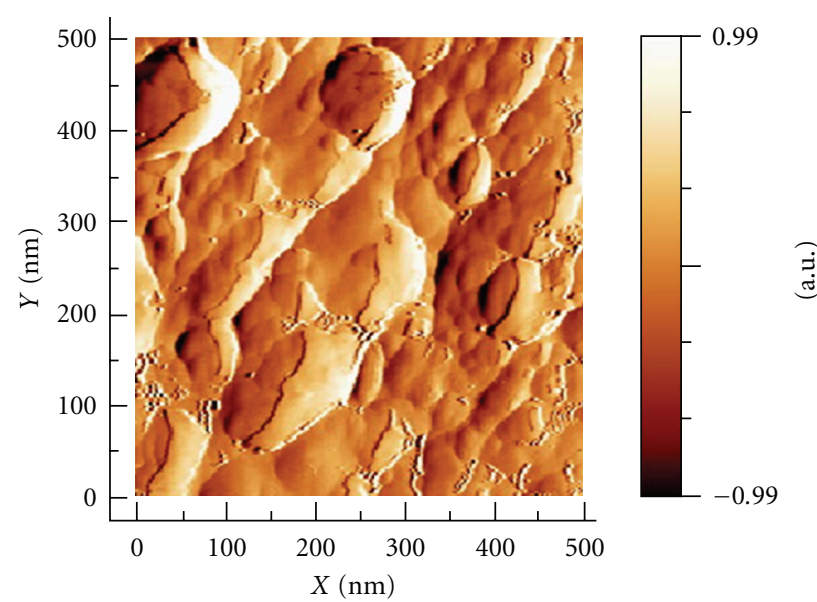

(b)

Figure 3: SEM (a) and AFM (b) of electrode type B (microdeposits on glassy carbon from the modifying solution of Pd to Au mixed in atomic ratio $90 \%: 10 \%)$.

TABLE 1: Electrode sensitivities (determined from the linear portions of the calibration graphs at temperatures 25 and 30 degree, correlation coefficients ranging between 0.98 and 0.99 ) and linear dynamic ranges of GC electrodes modified with microquantities of (Pd+Au) mixtures during hydrogen peroxide electrochemical reduction; temperatures 25 and $35^{\circ} \mathrm{C}$; phosphate-citrate buffer pH 7.0 ; reference electrode $\mathrm{Ag} / \mathrm{AgCl}(1 \mathrm{M} \mathrm{KCl})$.

\begin{tabular}{|c|c|c|c|c|c|c|c|c|c|}
\hline \multirow[t]{2}{*}{$E(\mathrm{mV})$} & \multirow[t]{2}{*}{$T\left({ }^{\circ} \mathrm{C}\right)$} & \multicolumn{4}{|c|}{$\begin{array}{c}\text { Sensitivity }\left(\mu \mathrm{A} \mu \mathrm{M}^{-1}\right) \\
\text { electrode type }\end{array}$} & \multicolumn{4}{|c|}{$\begin{array}{c}\text { Linearity }(\mu \mathrm{M})^{*} \\
\text { electrode type }\end{array}$} \\
\hline & & A & $\mathrm{B}$ & $\mathrm{C}$ & $\mathrm{D}$ & $\mathrm{A}$ & B & $\mathrm{C}$ & $\mathrm{D}$ \\
\hline \multirow{2}{*}{-100} & 25 & 0.27 & 0.42 & 0.28 & 0.47 & \multirow{2}{*}{900} & \multirow{2}{*}{800} & \multirow{2}{*}{870} & \multirow{2}{*}{830} \\
\hline & 35 & 0.27 & 0.45 & 0.40 & 0.55 & & & & \\
\hline \multirow{2}{*}{-50} & 25 & 0.26 & 0.35 & 0.19 & 0.36 & \multirow{2}{*}{800} & \multirow{2}{*}{980} & \multirow{2}{*}{1020} & \multirow{2}{*}{760} \\
\hline & 35 & 0.19 & 0.31 & 0.30 & 0.51 & & & & \\
\hline \multirow{2}{*}{0} & 25 & 0.25 & 0.31 & 0.14 & 0.30 & \multirow{2}{*}{680} & \multirow{2}{*}{900} & \multirow{2}{*}{830} & \multirow{2}{*}{800} \\
\hline & 35 & 0.12 & 0.23 & 0.21 & 0.35 & & & & \\
\hline
\end{tabular}

${ }^{*}$ Linearity ranges for all 4 types of GC electrodes were determined at $25^{\circ} \mathrm{C}$.

more extensive at $E=-100 \mathrm{mV}$. As the temperature increases and the potential shifts into positive direction, the linear dynamic range shortens, and the electrode sensitivity $(\mathrm{dI} / \mathrm{dC})$ increases (Table 2). At $E=-100 \mathrm{mV}$, the linear part of the calibration graph is shortened more than twice when the temperature is increased by $5^{\circ} \mathrm{C}$. Furthermore, higher background currents were registered at this potential. At a temperature of $25^{\circ} \mathrm{C}$, the electrode sensitivity at $E=-50 \mathrm{mV}$ is 2.2 times as high as that at $E=-100 \mathrm{mV}$, and at $30^{\circ} \mathrm{C}, 1.3$ times as high. The detection limits of glucose at $E=-50 \mathrm{mV}$ were found to be $9 \mu \mathrm{M}$, and at $30^{\circ} \mathrm{C}$ were found to be $6 \mu \mathrm{M}$ (estimated at signal/noise ratio of $3: 1$ ).

Therefore, the working potential of $E=-50 \mathrm{mV}$ was selected as optimal for determining glucose quantitatively. The experimental data on the selected working potential and temperatures 25 and $30^{\circ} \mathrm{C}$ were presented in Eadie-Hofstee coordinates $I_{s}$ versus $\left(I_{s} / C\right)$ in accordance with the equation $I_{s}=I_{s}^{\max }-K_{m} \cdot I_{s} / C$, where the steady-state electrode response $\left(I_{s}\right)$ for a certain concentration of the substrate is represented as a function of the electrode sensitivity at this given concentration $\left(I_{S} / C\right)$ (the ratio of the current
TABLE 2: Operational parameters of glucose oxidase enzyme electrode at temperatures 25 and $30^{\circ} \mathrm{C}$; applied potentials -100 and $-50 \mathrm{mV}$ ( $\mathrm{Ag} / \mathrm{AgCl}, 1 \mathrm{M} \mathrm{KCl})$; background electrolyte: phosphatecitrate buffer $\mathrm{pH}$ 7.0.

\begin{tabular}{lccccc}
\hline$E(\mathrm{mV})$ & $T\left({ }^{\circ} \mathrm{C}\right)$ & $\begin{array}{c}\text { Sensitivity } \\
\left(\mu \mathrm{A} \mu \mathrm{M}^{-1}\right)\end{array}$ & $r^{2}$ & $\begin{array}{c}\text { Linearity } \\
(\mu \mathrm{M})\end{array}$ & $\begin{array}{c}K_{M}^{\text {app }} \\
(\mu \mathrm{M})\end{array}$ \\
\hline \multirow{2}{*}{-100} & 25 & 0.05 & $0.96_{8}$ & 800 & - \\
& 30 & 0.11 & $0.96_{8}$ & 380 & 680 \\
\hline \multirow{2}{*}{-50} & 25 & 0.10 & $0.98_{2}$ & 450 & 710 \\
& 30 & 0.15 & $0.98_{5}$ & 300 & 405 \\
\hline
\end{tabular}

to the respective concentration of the substrate) (Figure 4). From the calibration graph, (Figure 4(a), left side) it is obvious that the linear dynamic range of the glucose oxidase enzyme electrode spans over the concentration range up to ca. $300 \mu \mathrm{M}$. From the presentation of these experimental data in Eadie-Hofstee coordinates (Figure 4(a), right side) it can be deduced that at low substrate concentrations (up to $\sim 300 \mu \mathrm{M}$ ), the sensitivity of the electrode remains 

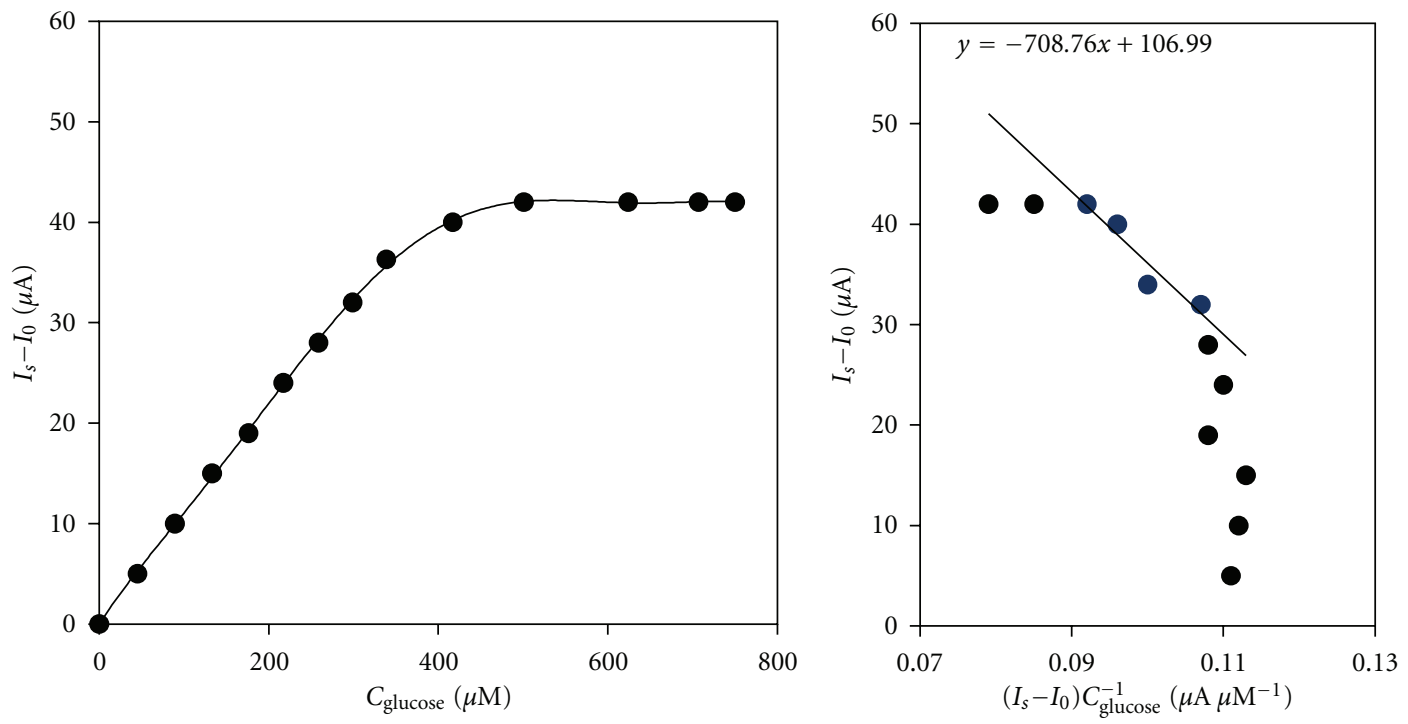

(a)
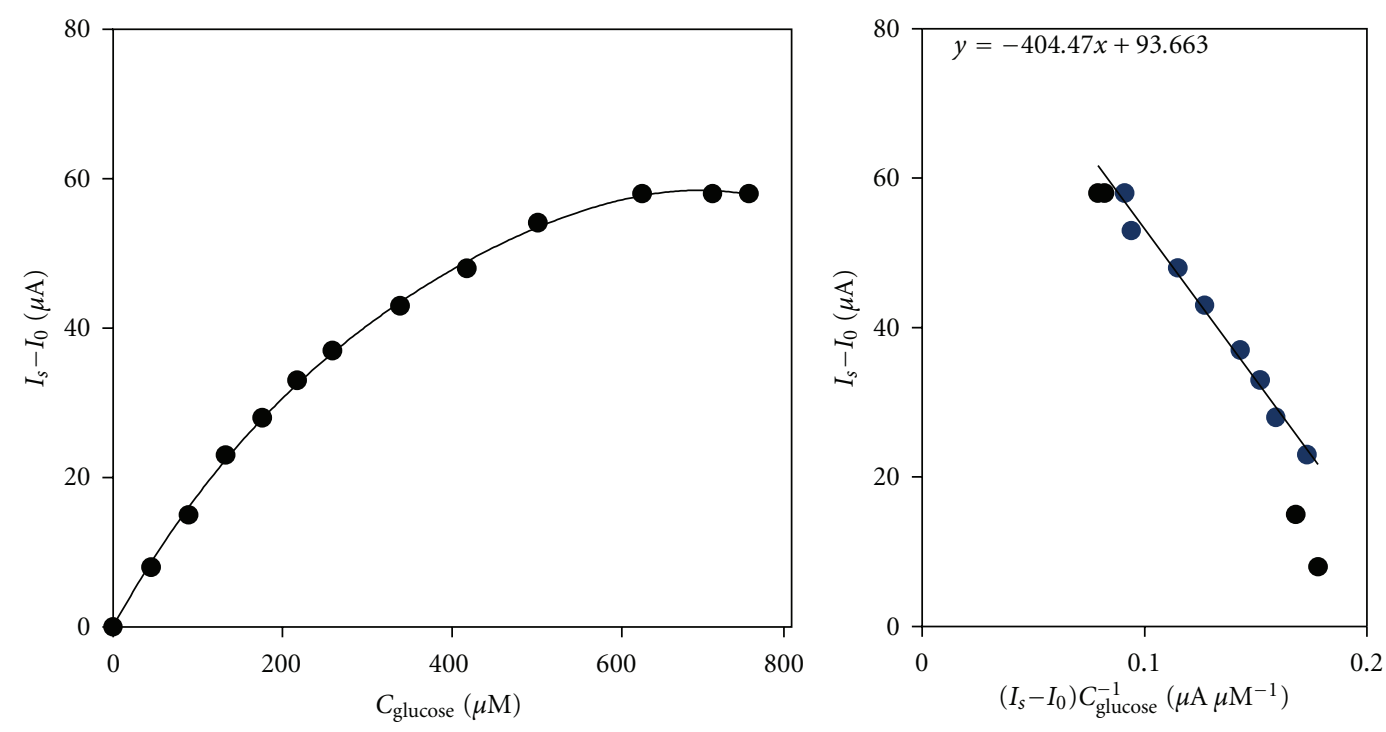

(b)

FIgURE 4: Calibration graphs (left sides) and Eadie-Hofstee plots (background subtracted steady-state current as a function of electrode sensitivity, right sides) registered at an applied potential of $-50 \mathrm{mV}(\mathrm{Ag} / \mathrm{AgCl}, 1 \mathrm{M} \mathrm{KCl})$; phosphate-citrate buffer, $\mathrm{pH} 7.0$; temperatures: (a) $25^{\circ} \mathrm{C}$, (b) $30^{\circ} \mathrm{C}$.

practically constant, which is typical for diffusion restrictions over the processes in the bioelectrochemical system. The inclined area between $300 \mu \mathrm{M}$ and $455 \mu \mathrm{M}$ indicates the presence of enzyme-kinetic control, while the horizontal area of the graph refers to high substrate concentrations exceeding $455 \mu \mathrm{M}$ and can be assigned to the effect of saturation of the enzyme with substrate molecules. It is due to the fact that it was impossible for the enzyme to react with all the glucose molecules that reach it. The value of the apparent Michaelis constant $K_{\mathrm{M}}^{\mathrm{app}}=710 \mu \mathrm{M}$ was determined from the slope of the inclined region. Analogous analysis related to the working mode of the electrode performed at a temperature of $30^{\circ} \mathrm{C}$
(Figure 4(b)) suggests that the same three working regimes of the electrode, diffusion, kinetic, and substrate limited, are present.

The diffusion area at this higher temperature, however, is considerably shorter (up to $130 \mu \mathrm{M}$ ) compared to that at $25^{\circ} \mathrm{C}$, while there is an increase in the section in which the electrochemical process takes place under kinetic control (from 130 to $635 \mu \mathrm{M}$ ). The value of the apparent Michaelis constant $K_{\mathrm{M}}^{\mathrm{app}}=405 \mu \mathrm{M}$ was found to be 1.8 times as low as the one determined at $25^{\circ} \mathrm{C}$. In Table 3, the operational characteristics of the examined electrode were compared to the ones of the glucose oxidase enzyme electrode, determined 
TABle 3: Operational parameters of glucose oxidase enzyme electrodes; applied potential - $50 \mathrm{mV}(\mathrm{Ag} / \mathrm{AgCl}(1 \mathrm{M} \mathrm{KCl}))$; background electrolyte: phosphate-citrate buffer $\mathrm{pH}$ 7.0.

\begin{tabular}{lccccc}
\hline $\begin{array}{l}\text { Electrode } \\
\text { type }\end{array}$ & $T\left({ }^{\circ} \mathrm{C}\right)$ & $\begin{array}{c}\text { Sensitivity } \\
\left(\mu \mathrm{A} \mu \mathrm{M}^{-1}\right)\end{array}$ & $r^{2}$ & $\begin{array}{c}\text { Linearity } \\
(\mu \mathrm{M})\end{array}$ & $\begin{array}{c}K_{M}^{\text {app }} \\
(\mu \mathrm{M})\end{array}$ \\
\hline type $\mathrm{A}_{\mathrm{GOx}}$ & 20 & 0.04 & $0.97_{7}$ & 550 & $>1600$ \\
& 25 & 0.10 & $0.98_{2}$ & 450 & 710 \\
\hline type $\mathrm{B}_{\mathrm{GOx}}$ & 20 & 0.08 & $0.96_{6}$ & 240 & 470 \\
& 25 & 0.13 & $0.97_{4}$ & 180 & 310 \\
\hline
\end{tabular}

through immobilization of GOx on porous graphite (GMZ), modified from a solution containing $\mathrm{Pd}$ and $\mathrm{Au}$ mixed in a ratio of $70 \%: 30 \%[10]$.

The glucose oxidase enzyme electrodes will be referred to as follows:

(i) the GOx-immobilised electrode based on modified $\mathrm{GC}$ (this work) - $\mathrm{A}_{\mathrm{GOx}}$ type;

(ii) the GOx-immobilised electrode based on modified GMZ-graphite [10]- $\mathrm{B}_{\mathrm{GOx}}$ type.

From the data presented in Table 3, it is evident that at both working temperatures the sensitivity of the type $\mathrm{B}_{\mathrm{GOx}}$ electrode is as high as 1.7 times $\left(\right.$ at $20^{\circ} \mathrm{C}$ ) and as high as 1.3 times $\left(\right.$ at $25^{\circ} \mathrm{C}$ ) compared to the sensitivity of the type $\mathrm{A}_{\mathrm{GOx}}$ electrode. The lower sensitivity of the type $\mathrm{A}_{\mathrm{GOx}}$ electrode is accompanied by linear dynamic range of the response that is 2.5 times as long, as well as with higher values of the apparent Michaelis constant $K_{M}^{\mathrm{app}}$. The differences in the operational parameters of the glucose oxidase enzyme electrodes shown above can be due to both the different proportions of $\mathrm{Pd}$ and Au microquantities in the modifying mixture, and to the different basic carbon matrix graphite and glassy carbon. These lead to a difference in the structure of the electrodeposited active phase [9] which eventually affects the conformation of GOx during its immobilization (which means it affects its activity).

\section{Conclusions}

Efficient electrocatalysts for the reduction of hydrogen peroxide at low potentials, around and below $0 \mathrm{~V}$ (versus $\mathrm{Ag} / \mathrm{AgCl}$ ), have been obtained by modifying glassy carbon matrices with microquantities of $\mathrm{Pd}$ and mixtures $(\mathrm{Pd}+\mathrm{Au})$, in different proportions of the catalytically active components. The basic kinetic $\left(E_{a}\right)$ and operation parameters (electrode sensitivity, linear dynamic range, and detection limits) of the electrodes in the target reaction have been resolved. A selective biosensor for amperometric determination of glucose based on electrocatalytic peroxide electrode of the Btype (Pd to Au mixed in atomic ratio 90\%:10\% deposits on glassy carbon) has been developed.

The following conditions have been established as optimal for determining glucose quantitatively:

(i) working potential of $-50 \mathrm{mV}$,

(ii) a temperature of $25-30^{\circ} \mathrm{C}$.
Under the above conditions, a detection limit of $6 \times$ $10^{-6} \mathrm{M}$, electrode sensitivity of $0.15 \mu \mathrm{A} \mu \mathrm{M}^{-1}$, and linear dynamic range of the response up to $300 \mu \mathrm{M}$ have been determined.

\section{Acknowledgments}

The authors acknowledge the support from the Bulgarian National Science Fund (Grant no. DVU-02/38).

\section{References}

[1] M. A. Rahman, M. S. Won, and Y. B. Shim, "Xanthine sensors based on anodic and cathodic detection of enzymatically generated hydrogen peroxide," Electroanalysis, vol. 19, no. 6, pp. 631-637, 2007.

[2] X. C. Tan, Y. X. Tian, P. X. Cai, and X. Y. Zou, "Glucose biosensor based on glucose oxidase immobilized in sol-gel chitosan/silica hybrid composite film on Prussian blue modified glass carbon electrode," Analytical and Bioanalytical Chemistry, vol. 381, no. 2, pp. 500-507, 2005.

[3] H. Nakatani, L. Santos, C. Pelegrine et al., "Biosensor based on xanthine oxidase for monitoring hypoxanthine in fish meat," American Journal of Biochemistry and Biotechnology, vol. 1, pp. 85-89, 2005.

[4] A. Arvinte, L. Rotariu, and C. Bala, "Development of a pesticides biosensor using carbon-based electrode systems," in Chemicals as Intentional and Accidental Global Environmental Threats, L. Simeonov and E. Chirila, Eds., pp. 337-343, Springer, The Netherlands, 2006.

[5] N. Dimcheva, E. Horozova, and Z. Jordanova, "A glucose oxidase immobilized electrode based on modified graphite," Zeitschrift fur Naturforschung, vol. 57, no. 7-8, pp. 705-711, 2002.

[6] P. J. Kulesza, R. Marassi, K. Karnicka et al., "Electrocatalysis and bioelectrocatalysis and nanostructured composite films," Reviews on Advanced Materials Science, vol. 15, no. 3, pp. 225233, 2007.

[7] L. Sun, D. Cao, and G. Wang, "Pd-Ru/C as the electrocatalyst for hydrogen peroxide reduction," Journal of Applied Electrochemistry, vol. 38, no. 10, pp. 1415-1419, 2008.

[8] Z. Taha and J. Wang, "Electrocatalysis and flow detection at a glassy carbon electrode modified with a thin film of oxymanganese species," Electroanalysis, vol. 3, pp. 215-219, 1991.

[9] E. Horozova, T. Dodevska, and N. Dimcheva, "Modified graphites: application to the development of enzyme-based amperometric biosensors," Bioelectrochemistry, vol. 74, no. 2, pp. 260-264, 2009.

[10] T. Dodevska, E. Horozova, and N. Dimcheva, "Electrocatalytic reduction of hydrogen peroxide on modified graphite electrodes: application to the development of glucose biosensors," Analytical and Bioanalytical Chemistry, vol. 386, no. 5, pp. 1413-1418, 2006.

[11] C. M. Welch, C. E. Banks, A. O. Simm, and R. G. Compton, "Silver nanoparticle assemblies supported on glassy-carbon electrodes for the electro-analytical detection of hydrogen peroxide," Analytical and Bioanalytical Chemistry, vol. 382, no. 1, pp. 12-21, 2005.

[12] E. Horozova, Z. Jordanova, and A. Angelacheva, "The effect of the nature of the electrode material on the oxidation rates of 
hydrogen peroxide, ascorbic acid, uric acid and gloutathione," Bulletin of Electrochemistry, vol. 13, no. 7, pp. 321-326, 1997.

[13] R. L. R. P. Fagury, K. O. Lupetti, and O. Fatibello-Filho, "Flexible potentiometric minisensor based on manganese dioxidecomposite for the determination of hydrogen peroxide in bleach and pharmaceutical products," Analytical Letters, vol. 38, no. 12, pp. 1857-1867, 2005.

[14] A. S. Kumar and S. Sornambikai, "Selective amperometric sensing of hydrogen peroxide with nafionlcopper particulates chemically modified electrode," Indian Journal of Chemistry Section A, vol. 48, no. 7, pp. 940-945, 2009.

[15] H. Ryoo, Y. Kim, J. Lee, W. Shin, N. Myung, and H. G. Hong, "Immobilization of horseradish peroxidase to electrochemically deposited gold-nanoparticles on glassy carbon electrode for determination of $\mathrm{H}^{2} \mathrm{O}^{2}$," Bulletin of the Korean Chemical Society, vol. 27, no. 5, pp. 672-678, 2006.

[16] L. Duan, Q. Xu, F. Xie, and S. Wang, "Hydrogen peroxide biosensor based on the bioelectrocatalysis of myoglobin incorporated in multi-walled carbon nanotubes/chitosan composite film," International Journal of Electrochemcal Science, vol. 3, pp. 118-124, 2008.

[17] A. Ernst, O. Makowski, B. Kowalewska, K. Miecznikowski, and P. J. Kulesza, "Hybrid bioelectrocatalyst for hydrogen peroxide reduction: immobilization of enzyme within organicinorganic film of structured Prussian Blue and PEDOT," Bioelectrochemistry, vol. 71, no. 1, pp. 23-28, 2007.

[18] S. Varma and C. K. Mitra, "Bioelectrochemical studies on catalase modified glassy carbon paste electrodes," Electrochemistry Communications, vol. 4, no. 2, pp. 151-157, 2002.

[19] V. M. Ivama and S. H. P. Serrano, "Rhodium-prussian blue modified carbon paste electrode (Rh-PBMCPE) for amperometric detection of hydrogen peroxide," Journal of the Brazilian Chemical Society, vol. 14, no. 4, pp. 551-555, 2003.

[20] K. Schachl, H. Alemu, K. Kalecher, J. Ježkova, I. Švancara, and K. Vytras, "Amperometric determination of hydrogen peroxide with a manganese dioxide-modified carbon paste electrode using flow injection analysis," Analyst, vol. 122, pp. 985-989, 1997.

[21] S. Arjsiriwat, M. Tanticharoen, K. Kirtikara, K. Aoki, and M. Somasundrum, "Metal-dispersed conducting polymer-coated electrode used for oxidase-based biosensors," Electrochemistry Communications, vol. 2, no. 6, pp. 441-444, 2000.

[22] K. Balasubramanian and M. Burghard, "Biosensors based on carbon nanotubes," Analytical and Bioanalytical Chemistry, vol. 385, no. 3, pp. 452-468, 2006.

[23] P. Yang, W. Wei, C. Tao, B. Xie, and X. Chen, "Nanosilver/multi-walled carbon nanotube composite films for hydrogen peroxide electroanalysis," Microchimica Acta, vol. 162, no. 1-2, pp. 51-56, 2008.

[24] M. Yang, Y. Yang, Y. Liu, G. Shen, and R. Yu, "Platinum nanoparticles-doped sol-gel/carbon nanotubes composite electrochemical sensors and biosensors," Biosensors and Bioelectronics, vol. 21, no. 7, pp. 1125-1131, 2006.

[25] R. Garjonyte and A. Malinauskas, "Amperometric sensor for hydrogen peroxide, based on $\mathrm{Cu} 2 \mathrm{O}$ or $\mathrm{CuO}$ modified carbon paste electrodes," Fresenius' Journal of Analytical Chemistry, vol. 360, no. 1, pp. 122-123, 1998.

[26] O. Niwa, "Electroanalytical chemistry with carbon film electrodes and micro and nano-structured carbon film-based electrodes," Bulletin of the Chemical Society of Japan, vol. 78, no. 4, pp. 555-571, 2005.

[27] T. Oyama, T. Okajima, and T. Ohsaka, "Electrodeposition of gold at glassy carbon electrodes in room-temperature ionic liquids," Journal of the Electrochemical Society, vol. 154, no. 6, pp. D322-D327, 2007.

[28] E. Alvarez and R. Salinas, "Electrochemically deposited Pd nanocrystals on vitreous carbon," in Proceedings of the 2nd Mercosur Congress on Process Systems Engineering, Rio de Janeiro, Brasil, 2005.

[29] P. J. F. Harris, "Fullerene-related structure of commercial glassy carbons," Philosophical Magazine, vol. 84, no. 29, pp. 3159-3167, 2004. 


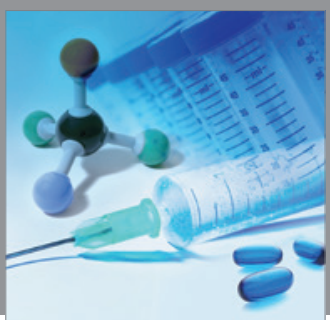

International Journal of

Medicinal Chemistry

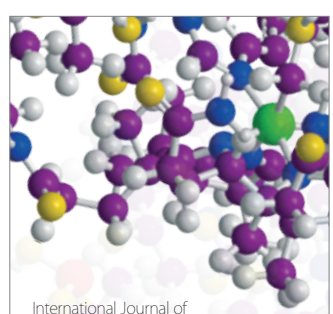

Carbohydrate Chemistry

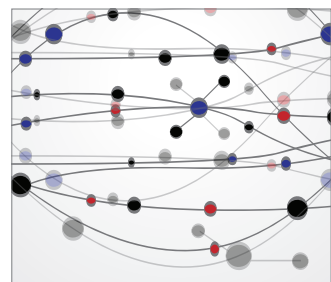

The Scientific World Journal
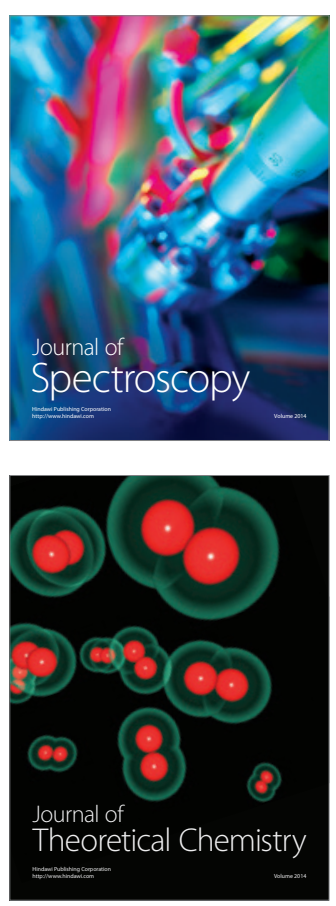
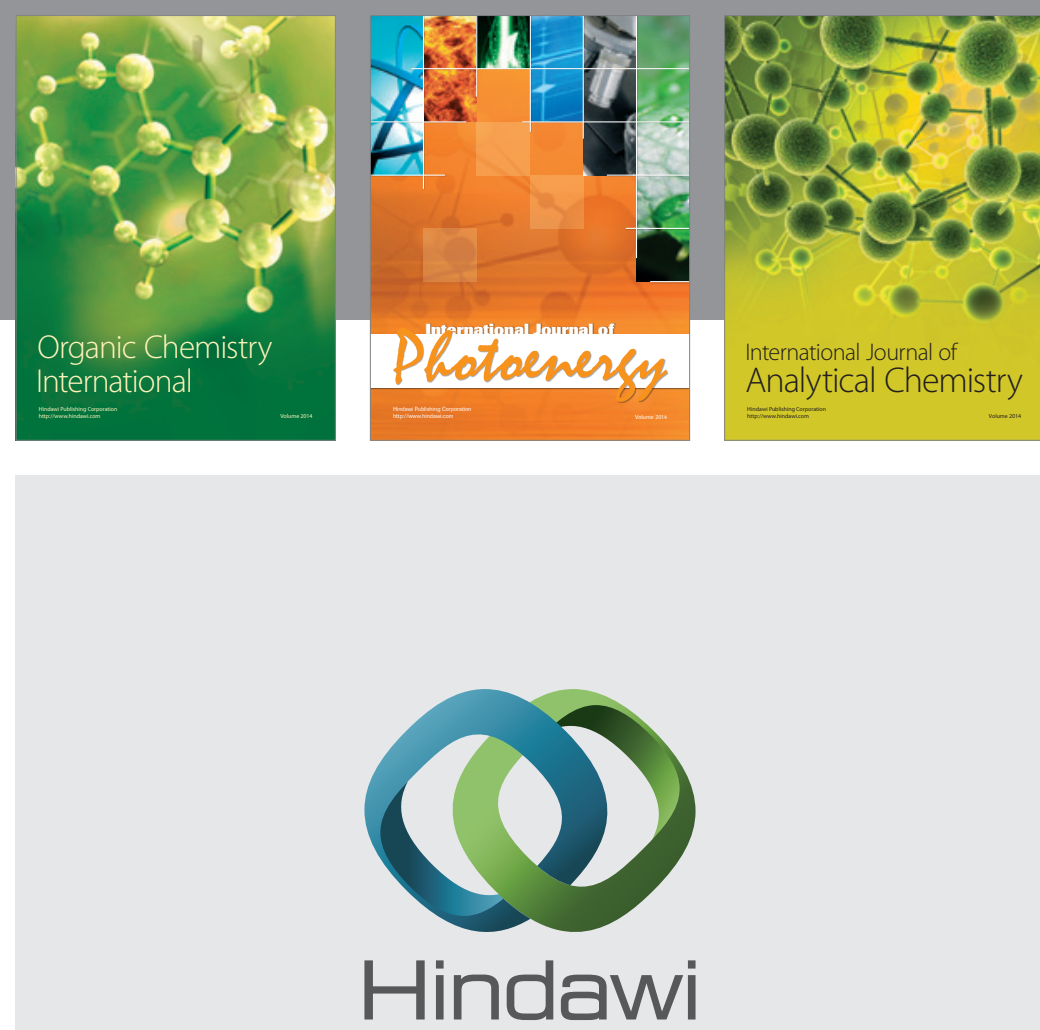

Submit your manuscripts at

http://www.hindawi.com
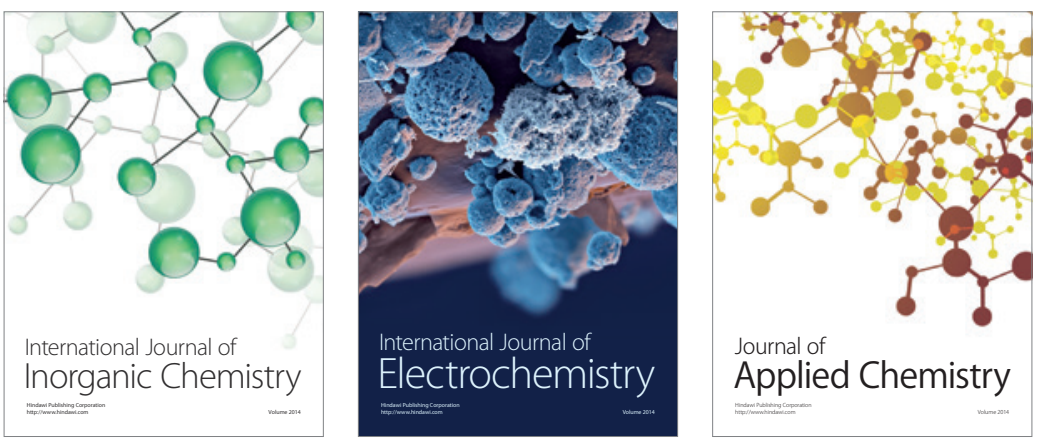

Journal of

Applied Chemistry
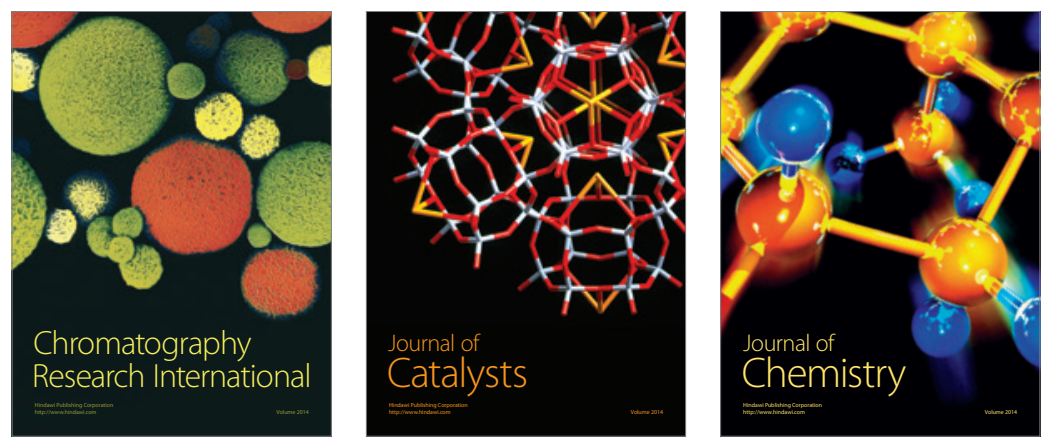
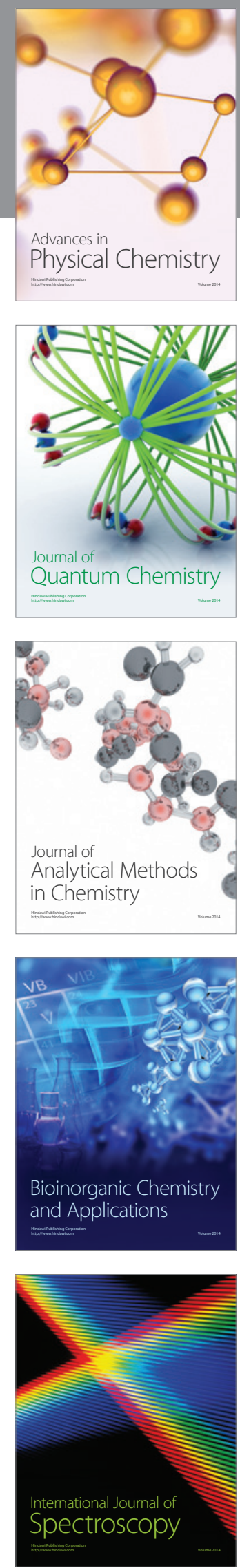